\title{
MicroscopyPioneers
}

\section{Nestor Zaluzec: \\ Next Question, Please}

\section{Cameron Varano}

The Pennsylvania State University, 201 Old Main, University Park, PA 16802

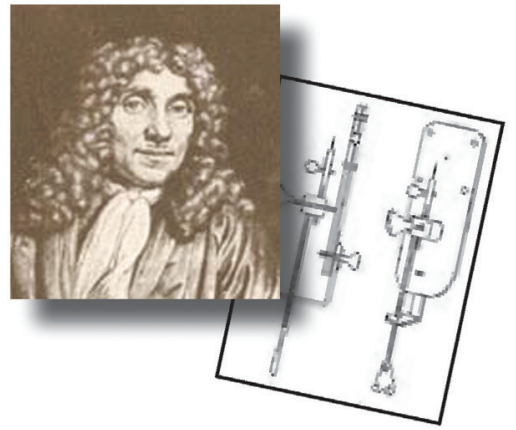

cvarano@psu.edu

Dr. Nestor J. Zaluzec was born and raised in the South Side of Chicago, IL in a family of five boys. While his brothers enjoyed playing sports in their free time, Zaluzec gravitated toward science. They all eventually left sports behind to pursue careers in engineering, medicine, arts, or chemistry, but for Zaluzec it seems he has always known his path. His career has been shaped by his ability to recognize

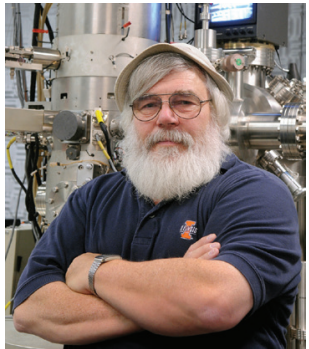

Nestor Zaluzec the need for new technologies and then build and implement those technologies. Zaluzec is looking for the interesting questions and is not bound by borders or scientific discipline. Consequently, he has found and helped cultivate a global community. One such example is the development of the TelePresence Microscopy Collaboratory (TPMC). Shortly after the web browser Mosaic came online (1993), Zaluzec launched TPMC to allow scientists and students around the world to access scientific resources. He fondly remembers that elementary school children would log on around lunchtime, knowing he would be around to share something amazing or to help with homework. The same year he launched the Microscopy Listserver, which, along with the TPMC, is still operating today and helping to unite the global microscopy community. While he is hesitant to agree on his "pioneer" status, he does admit that his scientific endeavors are "pushing the frontiers." We have all played enough Oregon Trail, however, to know that those who are on the frontiers are the pioneers.

One wonders if this is who Zaluzec is at his core or if it was cultivated by his experiences. He admits to being a natural tinkerer but can provide a lengthy list of impactful teachers and mentors beginning in grade school at Oliver Hazard Perry School. Outside of class, the Illinois Junior Academy of Science provided a continual outlet for young Zaluzec to explore his passion. When he speaks of his experiences there, it is easy to understand how impactful this opportunity was for him. It is not surprising that he is now a mentor in the program. The legacy he wants to leave is not simply his scientific accomplishments, but a new generation that has the same zeal for answering the scientific needs of the world.

Zaluzec's first notable foray in pioneering new technology occurred during his undergraduate years. He applied for and earned a position as a lab technician at Sherwin-Williams Research Center. The position relegated him to tasks such as washing test tubes. It was during this time that a programmable calculator arrived at the facility and sat idle. Zaluzec began to tinker and realized that he could program the calculator to do his homework. After a gruff inquiry regarding his activity, his superiors quickly realized that young Zaluzec's efforts were better spent at places other than the laboratory sinks. While at Sherwin-Williams he built a spectrogoniophotometer, fondly dubbed the "Nestorometer," (Figure 2) to analyze the light-scattering properties of paint. When asked about this, he laughed with a sense of pride, remembering that he only had a single color of wire and that it worked the first time. Zaluzec credits his training from teachers at Illinois Tech for providing him with the fundamental knowledge for that project. Zaluzec continued his part-time job at Sherwin-Williams until he graduated from the Illinois Institute of Technology in 1973. Upon graduating he, if you will pardon the pun, changed wavelengths and transitioned from studying the scattering properties of paints to metals.

By this point, word of his ability had spread and he received several offers for graduate school. Ultimately, he decided to pursue his doctorate at the University of Illinois, Urbana in metallurgy. The deciding factor was Dr. Hamish Fraser, his soon-to-be advisor. Fraser was a new faculty member who was interested in exploring important problems and looking for a student who could be his collaborator. It was his philosophy on "why we do what we do" that solidified Zaluzec's decision. He
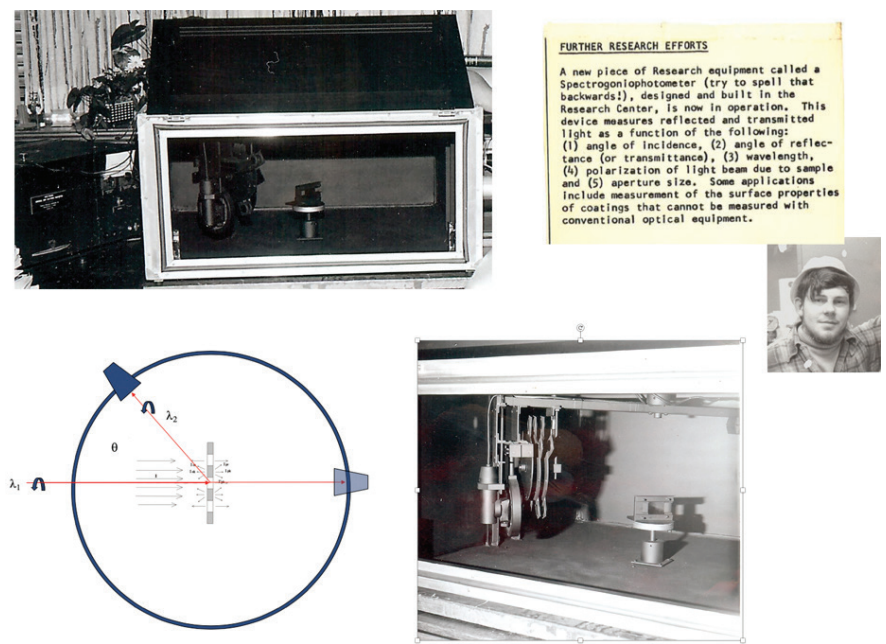

Figure 2: Details about the spectrogoniophotometer, also called the "Nestorometer," including a photo of Zaluzec from the early '70s. 
chuckles as he thinks back on this. "Sometimes we disagreed and he was right, other times it was me, or often we were both wrong." The necessity of failure, though, is one of Zaluzec's tenant beliefs. There are many cliché sayings regarding lessons learned from failures, but it is more than this for Zaluzec. Failing is an assurance that he is pushing the limits, and it brings forth the important questions he wants to answer: Why did it fail? What are the limitations? Why are there limitations? How can we work around or change those limitations? His aim is not to be state-of-the-art, nor to be the leading edge; he aims to be the "bleeding edge." He explains that the bleeding edge is different from the previous two because it is not stagnant.

In 1978, Zaluzec was awarded his doctorate, as well as the Eugene P. Wigner Fellowship, from Oak Ridge National Lab in Tennessee. He was there for two years before moving back to Illinois to work at Argonne National Laboratory. Still, Zaluzec remains a fellow at Oak Ridge to this day. At Argonne he became the first director of the Electron Microscopy Center. While his position then involved R\&D and administration, he is confident he is most useful in the lab. His record supports this statement. In 1996 he filed his first patent for a simultaneous specimen- and stage-cleaning device for an analytical electron microscope, what we now know as the Plasma Cleaner. This is arguably his most utilized invention. Perhaps the most notable of his inventions are the scanning confocal electron microscope and the $\pi$ Steradian Transmission X-ray Detector for electron-optical beam lines and microscopes. He received an R\&D 100 Award for the former in 2003 and the latter in 2010. The R\&D 100 Awards are given annually by Re $D$ World magazine to industry-changing products and technologies. For Zaluzec the inventions are the natural consequence of his desire to explore important knowledge gaps; they are not born of efforts to be disruptive. In his own words, "We want to be on the frontiers because that is where the interesting questions are-questions that need answers today."

His voice is giddy when he begins thinking of what he is currently working on and what challenges he wants to take on in the next 10 years. He laughs saying he needs multiples of himself and states with full confidence that he knows that some part of him will live on forever in silicon form. This is undoubtedly true. Then his body shifts, and for the first time his tone is somber. "What I really need to do is mentor the next generation to tackle these questions. Nothing is ever finished. There is no clear-cut end." Again, his record speaks to his efforts to cultivate the next generation of scientists. Zaluzec has been in a leadership position with the Illinois Junior Academy of Science since 1985, and he is an active member in eight professional societies. All of these efforts are to seek out and find those with queries. He jests that the worst thing you can do is ask him something, but many will attest that this is the polar opposite of the truth. Zaluzec is a scientist whose community spans the globe and whose technologies have expanded our knowledge. He wants nothing more than to help answer the world's most pressing problems. He is perhaps the most recognizable figure at microscopy meetings, so if you have a question seek him out. I assure you he wants to help you answer it.

Nestor J. Zaluzec may try to shrug off his pioneer status, but with forward-looking inventions and his innate desire to cultivate scientific community, he is indeed a pioneer on many frontiers.

\section{MINITOOL Precision Micro-Tools}

Efficient, precise and realistically proportioned
instruments are ideal for microscopists. Our
line of micro-tools includes needles, gravers,
chisels, knives, hooks and mirrors, probes,
spatulas, scribes and microrulers.
All 32 tools are offered singly or in sets of eight
tools with handles. Available in tip diameters
from .025mm to 1.00mm.
www.minitoolinc.com
info@minitoolinc.com

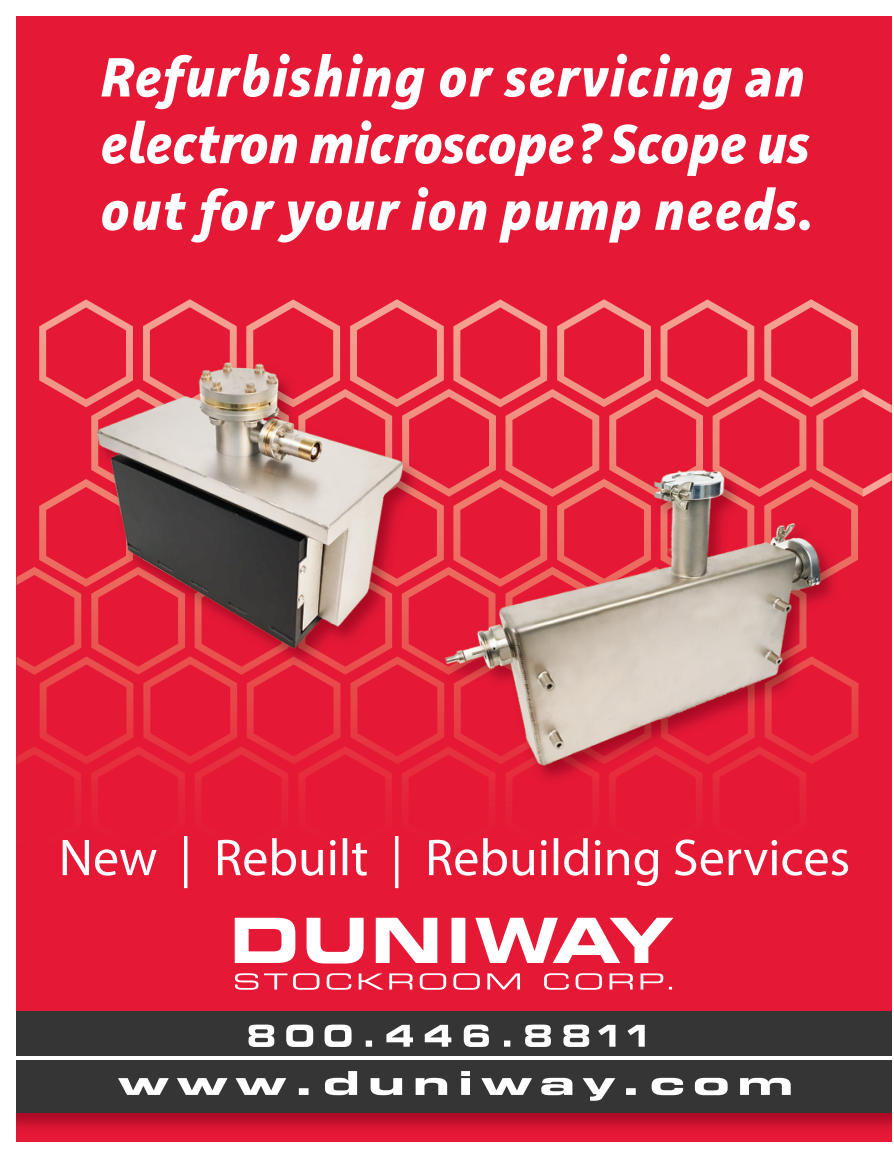

